\title{
La experiencia mexicana en la planeación de zrandes proyectos de inversión
}

\author{
Daniel Hiernaux Nicolas*
}

II artículo analiza la planeación de los grandes proyectos de inversión en México. in un primer tiempo, presenta brevemente el concepto de grandes proyectos de nversión, destacando la importancia que tuvieron en los años setentas y a inicios le los ochentas. A la fecha dichos proyectos han sido relegados por la situación le crisis, pero algunos de ellos ya han llegado a cierta consolidación de sus activiiades económicas básicas o se encuentran en proceso de reconvers:ón. Luego de lestacar las carencias del proceso de planeación a escala nacional (lo que tiene ma influencia evidente sobre los enfoques de los grandes proyectos en estudio), lemuestra que tanto la planeación empresarial por su modelo individualista, cono los tropiezos de la planeación pública de tipo sectorial e intersectorial, han ido obstáculos de importancia para el buen exito de los proyectos.

Por otra parte, al analizar la dimensión territorial de los grandes proyectos le inversión, sostiene que los proyectos se han construido al margen de una conepción clara de la región y por lo tanto de una planeación regional; paralelamene, el desarrollo y la planeación urbana han padecido de fuertes carencias por lo ue no se atendió debidamente las necesidades generadas por el crecimiento denografico urbano intensivo. Finalmente, destaca que la planeación estó intimanente relacionada con el sistema de poder y que su estudio no puede disociarse le este último.

\section{ntroducción}

.os grandes proyectos de inversión han constituido una modalidad signiicativa de intervención del Estado mexicano en el territorio desde fines le la década de los años sesenta hasta la fecha.

Por "grandes proyectos de inversión" entendemos situaciones en las uales un actor principal - generalmente el Estado en el caso mexicanomprende la realización de grandes inversiones sectoriales (acero, eneria, turismo etc.) que se enmarcan en un proceso de inversiones masivas $\mathrm{n}$ diversos rubros de apoyo o soporte a las actividades centrales y llegan transformar radicalmente el territorio circundante (Hiernaux, 1986).

El origen de la mayor parte de estos proyectos debe buscarse a fines e los años sesenta, a partir del momento en que empieza a frenarse el esarrollo del país en el contexto del relativo laissez-faire que representó 1 llamado modelo de "desarrollo estabilizador". Aunque se tienda a

* Profesor-investigador de la Universidad Autónoma Metropolitana, Unidad Xochimilco, reprèsentante en México e investigador del Centro de Investigaciones y Documentación sore América Latina (CREDAL), París, Francia. 
identificar los grandes proyectos (y muy particularmente algunos como Las Truchas) con la administración de Luis Echeverría, es notoriamente a partir de Díaz Ordaz, y quizás de López Mateos, cuando estos proyectos comienzan a definirse en el seno del sector público.

Buscar la justificación de esta situación, no resulta fácil. Manejaremos, no obstante, una hipótesis: consiste en que, aparentemente, el crecimiento económico del país, con escasa orientación programática de 1940 en adelante, empezaba a enfrentarse a serios cuellos de botella en los sesenta, los cuales justificaban una participación mayor del Estado en la economía, particularmente en sectores como el acero y la energía donde ya tenfan cierta participación, y que constituyen ramas de difícil inversión privada, entre otros factores por la magnitud de los costos de inversión. En el caso de los grandes proyectos turísticos, fueron concebidos en el marco de la necesidad creciente de generar divisas que el país no producia en las ramas productivas, entre otras causas por la fuga de divisas originadas en la transnacionalización de la economía. ${ }^{1}$

Finalmente, cabe recalcar que en la identificación y definición de dichos proyectos la banca internacional ha tenido un papel destacado. Buena parte de las decisiones deben remitirse a esferas internacionales; son éstas particularmente el Banco Interamericano de Desarrollo y el Grupo del Banco Mundial. ${ }^{2}$ Por lo tanto, asumimos la hipótesis de que los funcionarios mexicanos han recibido, por mecanismos diversos, influencias externas de alto nivel que han orientado sus actividades. ${ }^{3}$

Pero el objetivo de este artículo no es la reconstrucción de las corrientes de poder que se encuentran subyacentes a la formulación de los grandes proyectos a fines de los sesenta. Asumiendo que la decisión fue

\footnotetext{
${ }^{1}$ Todos los proyectos turísticos lanzados en México por el Estado se centran sobre tres objetivos explícitos que son: la generación de divisas, la creación de empleos y el desarrollo regional.

2 Es particularmente interesante revisar la orientación de los proyectos financiados por los organismos financieros internacionales: durante la época del desarrollo estabilizador, financiaron tanto la construcción de soportes materiales como la producción. La falta de participación privada en ciertas ramas los impulsó a "orientar" al gobierno mexicano hacia cierto tipo de proyectos: es notorio que Cancón recibió financiamiento del BrD; Ixtapa los recabó del Banco Mundial, así como los proyectos turísticos de San José del Cabo y Loreto. Por motivos que ignoramos, es el BID, y no el вM, el que financia ahora Huatulco. Por lo que a proyectos industriales se refiere, el BM ha tenido un papel destacado en el financiamiento de la siderurgia, los fertilizantes y algunas otras ramas.

${ }^{3}$ Esta afirmación se basa en mi experiencia como funcionario del gobierno, habiendo observado que el BM usa diversas "tácticas" para hacer pasar sus planteamientos: en primera instancia, manda regularmente misiones de análisis de ciertos problemas nacionales, regionales o sectoriales, las cuales toman contacto con funcionarios mexicanos. Las "misiones" destacadas en los paises para definir con el gobierno local la necesidad, el contenido y las condiciones de los créditos hacen también una fuerte labor de proselitismo, respaldada por asesores internacionales con nombres prestigiosos. Finalmente, el Instituto de Desarrollo Económico del Banco se encarga de la formación ideológica y técnica de los funcionarios de alto nivel.
} 
tomada por la intervención de diversos grupos de interés, tanto externos como internos, pretendemos dilucidar en qué medida ha existido una planeación de dichos proyectos.

Los niveles de análisis son múltiples y por demás interrelacionados: de lo nacional a lo local, de la empresa a la rama y al sector, varias interrogantes surgen para tratar de entender la modalidad de intervención del Estado en los grandes proyectos.

La planeación, tema central de este ensayo, se interpreta en este trabajo como la intervención organizada sobre objetos concretos, para orientar los procesos que atañen a dichos objetos hacia la consecución de objetivos considerados como deseables por los actores del proceso mismo de planeación. ${ }^{4}$

Revisaremos en los incisos que siguen el marco de la planeación nacional, el alcance de los grandes proyectos y la forma en que se llevaron a cabo los esfuerzos de planeación.

\section{El objeto de la planeación}

Tradicionalmente, la intervención estatal se había orientado a generar soportes para el desarrollo de otras actividades desempeñadas por el sector privado. Destacan particularmente los programas llamados de "infraestructura", como las carreteras, el riego o la electrificación del país, obras que constituyeron el sustento del crecimiento económico por tres décadas. A este modelo de intervención estatal, obedeció una modalidad de coordinación de las actividades públicas consistente en buscar una racionalización y priorización del gasto, en función de objetivos asignados al Estado por la esfera productiva. A tal enfoque correspondió la programación de inversiones realizadas en la época del desarrollo estabilizador, particularmente por la Secretaría de la Presidencia.

La nueva modalidad de intervención del Estado mediante su participación intensiva en el desarrollo de ciertas actividades generalmente productivas implica que el Estado debe fijar sus propios objetivos y, por tanto, determinar las estrategias y políticas a seguir para lograrlos. Más aún, la estrategia de desarrollo de grandes proyectos plantea la necesidad de acciones complejas que se derivan de ciertas características de los mismos:

-En primer lugar, se trata de procesos masivos de inversiones en tiempos relativamente cortos, si nos referimos a lo que realiza tradicio-

\footnotetext{
4 En el Diccionario el autor distingue entre planeación (proceso que va hasta el plan) y planificación, que implica la puesta en práctica de medidas, con vistas a alcanzar los postulados del plan. En este trabajo usamos el concepto de planeación en el sentido común de plan y proceso de ejecución.
} 
nalmente el Estado. Para el caso mexicano, destaca no sólo la magnitud absoluta y relativa de las inversiones en cada proyecto, sino además la existencia conjunta de varios proyectos en ejecución en la década de los setenta. Esto genera problemas de mayor envergadura que la existencia de un solo proyecto a la vez.

-También es significativo que la magnitud de los proyectos rebasa las capacidades tradicionales de la economía, tanto en disponibilidad de recursos financieros, como humanos, de tecnología, etc. Estos "cuellos de botella" han sido una caracteristica notoria de estos proyectos, particularmente porque afectan el proceso de edificación y operación de los mismos. Ante esta realidad, en el contexto de un modelo tradicional de gestión sería altamente recomendable desarrollar una planeación estratégica muy perfeccionada para lograr evitar los efectos "perversos" de las anteriores carencias, entre los cuales se puede mencionar la inflación que los proyectos inducen en la región donde se establecen. Como se sabe, éste no ha sido el caso y todos los grandes proyectos han producido tasas de inflación en su área de influencia muy superiores al promedio nacional.

-En tercer lugar, todos los grandes proyectos emprendidos de 1970 a la fecha se han localizado en zonas de escasa acumulación previa de capital, entre otras cosas porque la mayoría de éstos han dependido de la existencia de ciertos recursos naturales, pero también por la voluntad explícita de apoyar el desarrollo regional de las zonas de inversión. ${ }^{5}$ Esta situación exigía la confluencia de recursos mayores hacia los sitios de implantación para la realización de inversiones en ramas de "apoyo", como es el caso de las inversiones sociales. En consecuencia, la planeación se antojaba como un requerimiento imprescindible en el desarrollo conjunto de las diversas actividades necesarias para el buen funcionamiento del proyecto central.

- Vale mencionar que los recursos para la planeación difícilmente podían encontrarse en las regiones donde se implantaban los proyectos, lo que suponía un impacto obvio en la forma misma de realizar su planeación.

En síntesis, como objeto de planeación, los grandes proyectos plantean características específicas que no son tradicionales para el sector público y que, por lo tanto, modifican las modalidades de planeación o, por lo menos, deberian hacerlo. ${ }^{6}$

5 Ya hemos citado el caso de los polos turísticos que según el discurso oficial (estudios preliminares y planes nacionales y sectoriales) apoyan el desarrollo de regiones rezagadas. El discurso político de los presidentes siempre he epoyedo el postulado de user los grandes proyectos para epoyar el desarrollo regional.

${ }^{6}$ La planeación de los grandes proyectos debería caracterizarse por acciones integrades; éste no ha sido el caso en la experiencia mexicena. De ser asi, la planeación habría impli- 


\section{El marco de la planeación nacional}

Cuando los grandes proyectos se "cocinaban" en las oficinas püblicas, la planeación estaba muy lejos de su apogeo en el sistema tecnoburocrático mexicano. Se recordará que el primer esfuerzo importante de planeación en el país se remonta a los años treinta, cuando el Estado se está fortaleciendo y estructurando. Un grupo de profesionistas, entre los cuales destacaron los arquitectos y particularmente Carlos Contreras, impulsaron el decreto de la primera Ley de Planeación de $1930^{7}$ y algunos ensayos de planeación, sobre todo para la ciudad de México. Sin embargo, después del sexenio de Cárdenas se estimuló más un crecimiento vía los mecanismos de mercado, por lo que el Estado abandonó progresivamente la formulación institucional de planes.

En el curso de los treinta años subsecuentes, el gobierno y particularmente la Secretaría de la Presidencia, a partir de los años cincuenta, elaboró varios documentos que se refieren más a la coordinación de sus acciones, con un enfoque prioritario de programación antes que de planeación.

$\mathrm{Al}$ aparecer las iniciativas de los grandes proyectos a fines de los sesenta, es decir, al final del periodo de desarrollo estabilizador, la planeación de los proyectos es escasa en su etapa inicial, centrándose sobre todo en la programación de las actividades centrales del proyecto. Al respecto podemos tomar el caso de la siderurgia, pudiéndose demostrar la falta de planeación en los procesos de toma de decisión para la iniciación del Proyecto de Las Truchas.

Cuando se inicia el sexenio de Echeverria, el "proyectismo"8 es más significativo que la planeación, por lo cual los proyectos que ya habian tenido luz verde se implantaron en el marco de un fuerte voluntarismo que no podía esconder las fallas de ejecución, la existencia de cuellos de botella, etc. La prensa de la época se hizo eco de los problemas encontra-

cado una concertación entre sectores de actividad, sectores sociales y una necesaria reforma del sistema administrativo vigente.

7 El papel de los arquitectos ha sido decisivo en los primeros arranques de la planeacion en México. Por lo que hemos podido averiguar en una investigación relacionada con la planeación de la ciudad de México, se formo un grupo solido de profesionistas en torno a Contreras, que participaron tanto en la primera ley nacional de planificación como en la del Distrito Federal de 1933, el plan sexenal de Cárdenas y, finalmente, el Plan Regulador del Distrito Federal.

B Este término se usó en el siglo xvi para caracterizar una época en la que los funcionarios menores y algunos ciudadanos ilustrados hacian alarde de conocimientos de los problemas de la Nueva España; desarrollando proyectos al por mayor para presentar a las autoridades. La similitud con la época de Echeverria es interesante por el hecho de que las múltiples instituciones que él mismo cré sirvieron como "minas" de proyectos de diversos . tipos, pero en ausencia de una verdadera planeación. 
dos en Las Truchas, por ejemplo, mismos que fueron detallados en varias investigaciones. ${ }^{9}$ En cuanto a los nuevos proyectos, entre otros los turísticos, venían ya marcados por la carencia de organización de los anteriores por lo que su planeación y organización no resultaron mucho mejores.

En el curso del sexenio de Echeverría, la planeación nacional quedo más en el discurso político que en una realidad de manejo de los recursos públicos: la acción rebasó siempre los mínimos esfuerzos de planeación.

José López Portillo impuso un enfoque más cauteloso en los primeros años de su sexenio. Se recordará su planteamiento de "eficacia, eficiencia y coherencia" que, según él, iba a guiar la administración pública por seis años. Después de una reforma administrativa que cré́ una organización sectorial de la administración pública (diciembre de 1976), los primeros años fueron más de restricciones que de verdadera organización, como resultado del desorden existente cuando asumió el poder.

Una verdadera planeación no podía aún instalarse en el país, por lo que el Sistema Nacional de Planeación implantado por esa administración demostró la falta de un marco nacional que sólo se dará en 1980 con el Plan Global de Desarrollo 1980-1982; ${ }^{10}$ la incoherencia entre los planteamientos de los planes sectoriales, y, lo que más nos interesa, la falta del reconocimiento explícito de la existencia de grandes proyectos, constitutivos, sin embargo, de una porción importante de la intervención pública en la economía. En otros términos, los proyectos existían, se implementaban, pero no alcanzaban un lugar particular en la planeación institucional del sector público a nivel nacional o sectorial. ${ }^{11}$

Además, con la coyuntura del petróleo la administración de López Portillo rebasó rápidamente sus propios planteamientos, creando nuevos proyectos que escapaban a cualquier coordinación, incluso de su propia "cabeza de sector", como fue el caso de la Secretaría de Patrimonio y Fomento Industrial, por ejemplo. Cuatro proyectos esenciales de su administración caben en esta categoría: el petróleo, la atención a marginados con el Coplamar, el impulso de la agricultura de temporal con el SAM

${ }^{9}$ Véanse los libros publicados por El Colegio de México (investigaciones de Bizberg, Godau, Minello, Padua y Zapata), así como el libro colectivo coordinado por Restrepo (1985).

${ }^{10} \mathrm{El}$ Plan Global es publicado después del Plan Nacional de Desarrollo Urbano y del Plan Nacional de Desarrollo Industrial, por citar los más importantes; cuando se edita, el auge petrolero esté muy avanzado, por lo que ocurre un crecimiento sin guía general.

${ }^{11}$ La forma en que se ha dado la planeación en México demuestra una permanente desarticulación entre lo sectorial y lo nacional. Lo anterior se complica por los problemas ligados a la planeación territorial (vése después). De tal suerte, los planes nacionales, sectoriales y territoriales aun siendo redactados por los mismos grupos tecnocráticos nunca alcanzan une integración. Esto se reflejará también en las decisiones de inversiones, que no consiguen coherencia por proyecto. 
7, finalmente, el proyecto de Puertos Industriales, encargado con casi Jlenos poderes a su amigo Julio Rodolfo Moctezuma Cid.

El sexen io de Miguel de la Madrid no hace más que seguir en granies líneas la tendencia del sexenio anterior: desarrollar una planeación nstitucionalizada y burocratizada, organizada en un "sistema" que se juiere, o por lo menos se autocalifica, de más democrático.

El sistema de planeación que implanta Miguel de la Madrid corressonde a una voluntad expresa de remediar algunas incoherencias del sisema anterior, entre otras la indefinición en las responsabilidades de jjecución de los planes y la escasa jerarquización real que se logró entre 31 Plan Global de Desarrollo y los planes sectoriales.

Lo anterior se va a lograr efectivamente mediante el replanteamiento ie la Ley de Planeación de 1930, revisada con los enfoques y conceptos surgidos de la evolución del Estado mexicano 53 años después. Asimismo, el decreto del Sistema Nacional de Planeación Democrática de inizios de 1983 afianza una planeación legalista e institucional antes que cealista y práctica.

Sin embargo, el llamado a la planeación se contrapone con la limitazión del gasto público y la tendencia a la "retirada" masiva de toda la intervención pública. Leer el Plan Nacional de Desarrollo es reencontrar las mismas limitaciones que tenfa el Plan Global de Desarrollo: carencia de un marco serio de análisis de los grandes proyectos de inversión, que se diluyen en las acciones sectoriales; insuficiencia del estudio regional, эi cual se encuentra totalmente fragmentado, etcétera.

Si bien el Sistema Nacional de Planeación Democrática implica un avance serio en la institucionalización de la planeación, no ha hecho más que otorgar coherencia al proyecto gubernamental de implantar una planeación burocrática, excesivamente institucionalizada y poco acorde con las verdaderas necesidades de organización y previsión que supone intrínsecamente el uso del término de planeación, resultando, por lo tanto, aséptica.

Además, la planeación nacional no se ha planteado como un modelo flexible con determinaciones claras en términos de su adecuación a una coyuntura económica internacional cambiante. De tal suerte, los vaivenes del marco macroeconómico, más que demandar una modificación del plan inicial, obligan a proponer nuevos planes y programas que difícilmente se integran al Sistema Nacional de Planeación Democrática. Esta situación es evidente en la formulación del Programa de Aliento y Crecimiento (PAC) y en los diversos programas sectoriales de reconversión, particularmente el de la siderurgia y el de turismo, que se convierten en sustitutos de un sistema de planeación totalmente inadecuado para medidas concretas y urgentes.

Los grandes proyectos ligados a ramas especificas - la mayor de ellas, para bien o para mal, en proceso de reconversión- se relacionan 
obviamente más con los programas nuevos que con el Plan Nacional de Desarrollo, al que se ha acabado por no prestar mucha atención.

\section{La planeación de las empresas "motrices": el modelo individualista}

Los grandes proyectos se basan todos en el postulado, no siempre explícito, de promover una rama o una empresa motriz capaz de inducir la localización de nuevas empresas en su entorno, gracias al bien conocido efecto de polarización. Ideológicamente, la adopción de la teoría de los polos de desarrollo es plenamente reconocible tanto en el discurso de Echeverría como en el de López Portillo: empresas que atraerán nuevas empresas, industrias "industrializantes", polos económicos que generarán migración y, por lo tanto, apoyarán la descentralización de la región central, focos de distribución regional de ingresos, punto a partir del cual se difundirá la modernización del país, etc., son algunas de las ideas clave que se encuentran en el discurso público y dejan claramente entrever que los postulados esenciales de la teoría de la polarización económica y territorial están plenamente asumidos por el sector público.

Sin embargo, la experiencia no siempre positiva de otros países, como el caso de Ciudad Guayana en Venezuela, ${ }^{12}$ demostraba que la planeación era un requisito indispensable para la buena marcha de estos proyectos; también esto lo avalaban los desarrollos de la teoría tradicional de polos de desarrollo. Todo ello no parece haber surtido gran efecto sobre el manejo público en México: las empresas "motrices" se comportaban, y lo siguen haciendo, como simples unidades de producción, fuera de cualquier contexto de "polo" donde las colocaba el discurso público. En otros términos, las empresas públicas encargadas de una rama sólo se manejaban en el marco de su realidad empresarial, con criterios de costo-beneficio a su entera satisfacción, menospreciando totalmente la existencia de otros sectores de la economía y, más aún, una sociedad local que se encontraba "amarrada" a las empresas dominantes. La lógica del costo-beneficio, como lo han demostrado algunos autores como Samir Amin, es una lógica individual, basada además sobre postulados erróneos y, lo más importante, con efectos negativos para el resto de la economía y la sociedad.

Esta lógica de la ganancia individual es la que ha predominado en la planeación-programación de las empresas. Salirse de ella hubiera implicado que éstas se hubieran comprometido con los impactos de los proyectos que desarrollaban; situación, totalmente imposible en el marco del

12 Para el análisis de este caso existen varios textos de referencia; una síntesis reciente se encuentra en María Pilar García, en Restrepo, op. cit. 
funcionamiento de las empresas productivas públicas en el capitalismo subdesarrollado.

Es "normal", entonces, que en esta lógica individual empresarial, donde poco se distingue el sector público del privado, los impactos negativos de los proyectos hayan sido tan fuertes y, lo que es más, ignorados o delegados a otros; como ejemplo tenemos la contaminación total del río Coatzacoalcos, que es el resultado de la acumulación de los desechos producidos por empresas públicas como Pemex y Fertimex. Cada planta contamina; pero cada planta, y las empresas, consideraron por mucho tiempo que su planeación era individual y estrictamente limitada a la esfera productiva. Por tanto, "la contaminación no es su problema". ${ }^{13}$

La problemática urbana ilustra otra cara del mismo fenómeno: mientras la Siderúrgica Lázaro Cárdenas-Las Truchas (Sicartsa) construye la primera o la segunda etapa de su planta, los problemas urbanos, que "no son de su incumbencia", recaen sobre un fideicomiso asignado al sector asentamientos humanos (hoy desarrollo urbano, vivienda y ecología) cuyos recursos son totalmente insuficientes para atender la problemática que recae en sus funciones; aún más, la planeación urbana realizada por los organismos especializados, o por la propia secretaría, se ha topado con la falta de fluidez de la información que les impide así tener un conocimiento adecuado de los procesos económicos (empleo generado, inversiones, etc.), los cuales determinan los procesos sociourbanos que deben atender y orientar por la planeación.

La planeación de las empresas motrices no debe ser sólo analizada como un problema mismo del desarrollo y crecimiento de dichas empresas. Por lo general, encontramos que la planeación de las empresas públicas en los grandes proyectos se ha limitado a organizar y ver por el funcionamiento básico de la planta, ignorando los fenómenos provenientes del entorno como las contingencias financieras y otras. En efecto, cualquier empresa del sector privado tiene que hacer frente a un entorno las más de las veces negativo que la obliga a realizar una planeación cautelosa, no sólo de su proceso de producción, sino además de factores de orden social, político, financiero, etc. No es el caso de la empresa pública, la cual asume que no existen estos problemas, eventuales cuellos de botella, ya que otras estructuras estatales actuarán como "estado benefactor" ("Welfare State") para resolver los problemas del entorno.

En consecuencia, se puede decir que las técnicas de planeación y administración estratégicas, como las que usan cada vez más en otros países

${ }^{13}$ Este problema se presenta en todos los grandes polos, donde las empresas muestran un interés muy residual en la protección del medio ambiente o las condiciones de vida de la población. Esto se refleja en la priorización de las inversiones públicas que demuestran siempre la preferencia para lo "productivo" antes que por lo "social". 
del mundo, son poco conocidas por la planeación pública o, por lo menos, escasamente aplicadas.

Aun en el marco de su propio proceso de producción, la planeación de las empresas es limitada, ya que no se toman en cuenta muchos factores, ni se ejercen los mismos criterios de rentablidad que en el sector privado pues las cuentas no se rinden a los accionistas, sino a funcionarios comisionados en consejos de administración.

\section{La planeación intersectorial}

Asumiendo ya los defectos inherentes a la planeación de las empresas mismas, cabe interrogarse sobre la existencia de una planeación entre empresas de una misma rama o de ramas diferentes. Algunos esfuerzos se pueden señalar, como ha sido la creación de Siderúrgica Mexicana (Sidermex), que supuestamente se cré́ para tal fin. Desgraciadamente, la concertación ha resultado escasa y los resultados poco reconocibles. Aspecto tan importante en la planeación como es la coordinación de los insumos no se ha logrado en los grandes proyectos, a pesar de que se trata de una coordinación factible entre empresas públicas. Tareas de interés común, tenían que haber reunido en torno a la mesa de concertación a Petróleos Mexicanos, Comisión Federal de Electricidad, la Secretaría de Recursos Hidraúlicos, y la Secretaría de Asentamientos Humanos y Obras Públicas para garantizar el adecuado suministro de energía eléctrica, de gas o combustibles derivados del petróleo, de agua industrial y potable, etcétera.

Asimismo, la localización de los grandes proyectos en sitios aislados con un nivel de desarrollo mínimo provocaba la necesidad de una concertación-planeación importante con las instituciones a cargo de carreteras, aeropuertos, etc. No ha sido así, pues cada rama o sector ha actuado, y lo sigue haciendo, en forma individual, sin reconocer ni medir adecuadamente las necesidades mutuas. ${ }^{14}$

Lo anterior es el resultado de una división en sectores que si bien cumplen ciertas funciones importantes dentro de cada rama no permiten, aun con la presencia de una Secretaría de Programación y Presupuesto, una interrelación adecuada entre empresas, instituciones, ramas y sectores.

La planeación de las empresas y de los proyectos tampoco ha demostrado una capacidad importante de integrar al sector privado en la

\footnotetext{
14 En el caso de Las Truchas, en la reunión de gabinete que condujo a la aceptación del proyecto por Echeverría, varios secretarios expresaron su desacuerdo en el arranque por no haberse considerado los efectos en otros sectores. En éste como en los otros casos de grandes proyectos, la decisión fue antes que todo presidencial.
} 
ormulación y operación de las actividades. En buena medida, la planea:ión se ha manejado como del sector público, para el sector público, y in ausencia de cualquier otro actor económico, social o político.

En este.sentido, cabe rescatar la experiencia del proyecto de puertos ndustriales. En este caso, la Coordinación de Proyectos de Desarrollo ;fectuó sondeos importantes tanto en el país como en el extranjero (entre Jtros, en Japón) para descubrir el interés de ciertas empresas a localizarse $m$ los proyectos. Sin embargo, el contacto con el mercado potencial del ugar no es garantía de la localización de sus empresas. De tal suerte, los Jlanes maestros de las áreas industrial-portuarias demostraron inconzruencias tales como la propuesta de una zona para fábricas de comporentes aeronáuticos en el Puerto Industrial de Ostión-Coatzacoalcos.

Una situación similar se presenta con todas las instituciones públisas que se dedican a proveer soportes materiales para la instalación de zmpresas, tanto en el caso de los parques industriales como el del Fondo Nacional de Fomento al Turismo. ${ }^{15}$

\section{Proyectos sin región}

La planeación de los grandes proyectos en México se ha realizado en una situación de singular dicotomía entre el discurso regional y la práctica de la intervención en ese ámbito. En efecto, por una parte, los grandes proyectos se han manejado como un instrumento privilegiado de la planeación regional para el desarrollo de áreas con retrasos serios y poca integración al modelo socioeconómico vigente a nivel nacional. Por otra parte, las políticas y medidas regionales han sido escasas y pobres los esfuerzos de planeación regional.

La gestión regional y su planeación han sido muy limitadas. En el sexenio de Luis Echeverría el concepto de región tenía cierto vigor, gracias, entre otros factores, a la presencia de regionalistas en grupos asesores del gobierno y en las principales instituciones académicas. A excepción de algunas instituciones como las comisiones por cuencas hidrológicas, cuya influencia fue cada vez más limitada, la intervención pública demostró ser antes que nada sectorial, con escasa preocupación por internalizar los efectos positivos y minimizar los negativos que surgen de la inserción de proyectos con fuerte capacidad de distorsión, en espacios cuyas estructuras económicas, sociales, políticas y territoriales, resultaban ser muy débiles.

${ }^{15}$ El éxito de los polos turisticos (principalmente Cancún) no se debe a la adecuada planeación de las infraestructuras con relación a la demanda, sino sencillamente a que las devaluaciones sucesivas han logrado mantener a flote actividades que no han logrado una fuerte productividad. 
Para inicios del sexenio de López Portillo, ${ }^{16}$ el concepto de región había perdido ya la escasa relevancia que había logrado en el sexenio anterior. La Dirección General de Programación Regional realizó sin lugar a duda muchos estudios internos, sin que éstos llegaran a trascender en la formación de una verdadera programación regional, ya que su participación en el proceso de toma de decisiones quedó muy débil, particularmente en lo referido a las autorizaciones presupuestales, uno de los pilares de la política regional.

La carencia de una dimensión regional de los grandes proyectos en las políticas públicas es una característica que diferencia esta experiencia de la de otros países, y obedece en buena medida a la incapacidad, aún vigente, de armonizar las necesidades de una concertación-planeación regional con los principios federalistas que impiden el establecimiento de órganos supraestatales, a excepción del nivel federal.

Esta carencia de imaginación tecnopolítica explica por qué cada vez más, y en forma particularmente notoria a partir del sexenio de Miguel de la Madrid, el enfoque regional se ha desviado hacia "lo que no se hace en la zona centro". Un libro, prologado por el propio presidente, es quizás el mejor ejemplo de este punto de vista finalmente anti o arregional, en el que se borra la consideración de la región como una unidad social, económica, política y territorial explícita, sustituyendo una verdadera política regional por la acumulación de obras inconexas en espacios periféricos.

Curiosamente, ni siquiera en los "planes regionales" se ponen en evidencia los grandes proyectos como posibles elementos "motrices" de la política regional. Cada enfoque sectorial de los planes regionales haré una breve referencia a los grandes proyectos, mientras la integración regional, la toma en cuenta de los impactos regionales y las proposiciones que de ello deberían derivarse, nunca aparecen nitidamente remarcadas en el plan regional. Refiriéndose al caso del sureste, por ejemplo, hubiera sido importante que en el plan regional respectivo, se hubiera significado el papel de Cancún, por una parte, y de las zonas petroleras, por la otra, como posibles detonadores de transformaciones regionales. Ninguna referencia seria se puede encontrar al respecto y, lo que más inquieta, es que el "espacio" regional no aparece expresamente delimitado en una referencia gráfica. ${ }^{17}$

Los grandes proyectos quedaron huérfanos de región, al mismo tiem-

${ }^{16}$ El sexenio de López. Portillo consagra lo que hemos llamado en otro trabajo "la visión urbana del territorio" (véase Hiernaux: 1985).

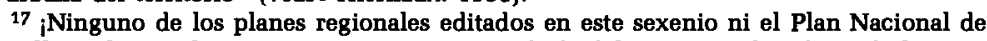
Desarrollo incluyen alguna representación cartografiada del espacio trabajado ni de las propuestas! 
Io que las regiones resultarían huérfanas de proyectos integrales en los ue se pudiesen plasmar los postulados de las políticas regionales.

\section{i. El crecimiento urbano con planes y sin planeación}

II sexenio de López Portillo se ha reconocido como el de mayor impulso a la planeación de centros de población. Iniciada a fines del sexenio de icheverría, la política de planeación urbana ya había conocido cierto resonocimiento por parte de las instituciones que manejaban el desarrollo urbano de los grandes proyectos.

Dos ejemplos son particularmente explícitos: Cancún, donde el Fileicomiso de Infraestructura Turistica (Infratur - hoy Fondo Nacional de ?omento al Turismo (Fonatur) - había mandado realizar un plan urbano lesde fines de los sesenta, y Las Truchas, donde el Instituto de Desarrollo le la Comunidad y de la Vivienda Rural (Indeco), ${ }^{18}$ y posteriormente el ?ideicomiso Lázaro Cárdenas, realizaron sendos estudios de planeación irbana en los primeros años de los sesenta, antes del "boom" de la planeıción urbana. En ambos casos, resalta la voluntad de desarrollar la "ciulad ideal", capaz de alojar "armónicamente" a la población inducida jor el turismo y la siderurgia, respectivamente.

Los dos proyectos se caracterizaron por un enfoque tecnificado, hasa modelizado por computadora el segundo, pero con escaso reconociniento de lo que significaba la creación de una ciudad nueva por parte iel Estado y la factibilidad real de que la sociedad mexicana se moldeara ll prototipo de ciudad y de vida urbana estereotipada que proponfa la slaneación.

Puerto Juárez y Guacamayas, respectivamente, vinieron a demostrar que puede haber planes sin adecuación a la realidad, pero también planes in planeación..$^{19}$ Por esto, se entiende que las propuestas, aparte de ser poco realistas, no fueron acompañadas de los mecanismos adecuados de ejecución que hubieran garantizado su éxito. De hecho, la planeación urbana de los grandes proyectos se ha realizado en el escritorio, con pocos sontactos con la realidad y, por lo tanto, sin los necesarios nexos con la situación institucional prevaleciente. Probablemente, el nivel más bajo experimentado lo constituya la planeación urbana municipal, realizada en el sexenio de López Portillo por la SAHOP: la Dirección General de Or-

${ }^{18}$ El Instituto Nacional del Desarrollo de la Comunidad y de la Vivienda Popular, creado por Luis Echeverría a inicios de los setenta, ha realizado varias acciones de planeacion urbana en épocas tempranas, en forma similar y paralela a las que desarrollaba la Secretaria del Patrimonio Nacional.

${ }^{19}$ Nos referimos aqui a la diferencia establecida por Ortega Blake entre la preparación de un plan-documento y los mecanismos que garantizan su ejecución. 
denamiento Territorial de los Asentamientos Humanos ${ }^{20}$ realizó un proyecto homogéneo de Plan Urbano Municipal, vulgarmente reconocido como "machote". Teniendo sólo que rellenarse con palabras las claves repetitivas en los planes, se realizaron cientos de ellos, sin que se percibiera el más mínimo nexo entre, por una parte, la planeación, y por la otra, la programación y ejecución de proyectos de desarrollo urbano.

Otra característica de la planeación urbana del periodo 1978-1982 fue el contratismo: la mayor parte de los estudios fueron realizados por empresas consultoras que, en su mayoría, no tenían antecedentes de los sitios que iban a planificar, desplazaban poco personal para realizar trabajo de campo y, quizás lo más grave, no adquirían responsabilidad formal sobre sus propuestas.

Obvio es que en estas condiciones la gran cantidad de estudios realizados sobre los diversos lugares de los grandes proyectos no cumplieron ni mínimamente con los requerimientos reales de planeación efectiva de los mismos. Además, ignoraban generalmente las tendencias económicas de estos sitios, ya porque las empresas que se establecieron no les pasaron los datos, o por simple desinterés, por lo cual las propuestas de ordenamiento del espacio urbano no reflejaban ni tomaban en cuenta las transformaciones reales de los espacios estudiados.

En tales condiciones, es evidente el divorcio entre la planeación urbana y las acciones específicas del Estado en México.

\section{Planeación y sistemas de poder}

El último elemento que queremos abordar en este ensayo es la cuestión de las correcciones entre los mecanismos de planeación y los sistemas de poder.

El plan, con su buena dosis de páginas y planos, es sin lugar a dudas un elemento de poder para sus formuladores. No tanto para el consultor que resulta ser el brazo técnico del proceso, sino sobre todo para la institución que lo contrata. Por ello, las dependencias públicas quieren realizar tantos planes como les sea posible, como fue el caso de los cientos de planes municipales, cuyo número se convirtió en la medición de los esfuerzos de planeación en los tres últimos sexenios.

Independientemente de la calidad técnica del trabajo realizado, de la veracidad de la información o de la bondad de las proposiciones, el sim-

20 Esta dirección recibió funciones ambiguas para trabajar de la escala superior a la intraurbana, pero no desde un punto de vista regional integral, sino desde la perspectiva dé los asentamientos humanos exclusivamente. Esto dio lugar a la publicación de documentos del tipo "plan regional de desarrollo urbano de los asentamientos humanos". 
pie hecho de verter elementos escritos en un plan otorga poder burocrático al que dirigí́ el proceso. Ésta es parte de la explicación de por qué la planeación urbana y sectorial no se ha logrado descentralizar hacia los niveles de gobierno, que realmente tienen a su cargo la gestión de las empresas o de los territorios.

En el caso de la siderurgia, ocurre que la empresa Sicartsa, que se localiza en Ciudad Lázaro Cárdenas-Las Truchas, ha perdido totalmente su capacidad de influir en los procesos importantes; su planeación se ha diluido en una honesta administración con vistas a mejorar los procesos productivos existentes, mas no en tomar decisiones centrales sobre el futuro de la planta, la realización de su segunda etapa y, por ende, el futuro mismo de este gran proyecto nacional. ${ }^{21}$

Por lo que se refiere a la planeación del territorio, tanto en su dimensión regional como en la urbana es innegable que la Secretaría de Programación y Presupuesto, para lo regional, y la Secretaría de Desarrollo Urbano y Ecología, para lo urbano, se han negado a romper con el centralismo planificador, argumentaban que los poderes locales no tienen la capacidad técnica para realizar los planes ni los recursos financieros suficientes para su ejecución, además de existir una mayor propensión a la corrupción. Tales argumentos han propiciado que la planeación no haya podido escapar del poder central. Los planes, aun en este sexenio de supuesta descentralización de la vida nacional, se siguen manejando como botín de las instancias federales.

Como mecanismos de descentralización de la planeación urbanoregional, se han creado instancias semidescentralizadas constituidas por diversos fideicomisos y empresas paraestatales con capacidad real de desarrollar una planeación más cercana a la realidad, con datos fidedignos, a menor costo y, sobre todo, con la potencialidad de lograr que las decisiones cuenten con una participación real y progresiva de las instancias locales y de la población.

No obstante, la planeación de los grandes proyectos, tanto en sus niveles económico y social como territorial, se ha mantenido como mecanismo de poder para funcionarios de la federación, a expensas de lograr una mayor efectividad mediante su descentralización y democratización.

${ }^{21}$ Las decisiones rebasan el nivel de la empresa, incluso de Sidermex, y son sometidas a los vaivenes de decisiones presidenciales respaldadas por asesorías de funcionarios, en las cuales no se descarta que se trafiquen influencias, visiones e intereses de política de grupos, etc., así como otros factores igualmente negativos. 


\section{Conclusiones}

En el sexenio de Miguel de la Madrid los grandes proyectos se han relegado a un segundo plano por la escasez de recursos financieros disponibles. Consiguientemente, los proyectos ya realizados, pero que requerían de atención especial para resolver una problemática socioespacial -por ellos inducida en la época de bonanza - no han sido adecuadamente atendidos; este es el caso particular de Lázaro Cárdenas-Las Truchas. Por otra parte, la consolidación de ciertas actividades económicas sólo se ha realizado de manera insuficiente y con escasa planeación; la segunda etapa de Sicartsa es un buen ejemplo de ello.

En nuestra opinión, existe cierta incapacidad política detrás de estos procesos de inversión interrumpidos que da por resultado una cierta "política de avestruz", la cual no se compromete en señalar prioridades, tiempos y montos para consolidar lo invertido y garantizar un mínimo de bienestar para la población. Obvio es que las carencias a nivel nacional se reflejan en los grandes proyectos. Sin embargo, estos grandes proyectos son vitales para la economía mexicana: ¿qué proponer para el acero mexicano?, ¿cómo desarrollar la petroquímica?, ¿cómo plantear el papel del turismo en la economía?

No existen respuestas oficiales para este tipo de cuestiones, y los titubeos en las acciones demuestran la carencia de una política nacional coherente. Adicionalmente, y aunque esto sería tema de otro trabajo, está claro que las políticas desarticuladas de los últimos años apuntan más a una desintegración de los grandes proyectos públicos por su clara voluntad de declarar privadas muchas ramas de la producción. Esta "reconversión" es también un proceso de desintegración de importantes actividades económicas regionales y una contradicción insuperable con los planteamientos regionales establecidos simultáneamente.

Aun en el caso de que existiera un consenso democráticamente establecido en apoyo a la desincorporación del Estado de los grandes proyectos, sería necesario realizar una prolija planeación como vía para minimizar los impactos negativos de la restructuración económica y las pérdidas de empleo por el desmantelamiento de la planta productiva.

\section{Bibliografia}

Amin, Samir (coord.) (1975) La planification du sous-dévelopment, Anthropos, Paris.

Bisberg, lian (1982), La acción obrera en Las Truchas, México, El Colegio de México. Boisier, Sergio (1974), "Industrialización, urbanización, polarización: haçia un enfoque unificado" en Planificación regional y urbana en América Latina, México, Siglo XXI. 
Cassasus, C. y Daniel Hiernaux D. (1987), Espace industrial, espace social, (comparaison Las Truchas-Fos/s/mer), C.N.R.S., París.

De la Madrid, Miguel (1985), 31 experiencias de desarrollo regional, SPP-SEP, México, Foro 2000.

García, María P. (1985), "La Guayana Venezolana: otro caso aleccionador" en Las Truchas ¿inversión para la desigualdad?, México, Cecodes-Océano, p. 233-276.

Godau, Rainer (1982), Estado y acero en Las Truchas, México, El Colegio de México.

Hiernaux, Daniel (1987), 'L'État et le territoire: bilan de trois sexennats de politiques urbaines et régionales au Mexique (1970-1985)" en Revue Internationale d'Action Communautaire, 17/57.

(1986), "Los grandes complejos industriales, el caso de México", en Revista Interamericana de Planificación, vol. XX, núm. 79, septiembre, pp. 45-55. Estado y siderurgia en el marco de la reconversión, México, Universidad Autónoma Metropolitana-Xochimilco, en prensa.

Minello, Nelson (1982), Siderurgia Lázaro Cárdenas-Las Truchas: historia de una empresa, México, El Colegio de México.

Ortega Blake, José Arturo (1982), Diccionario de Planeación y Planificación (un enfoque conceptual), Edicol, México.

Restrepo, Iván (coord.) (1985), Las Truchas ¿inversión para la desigualdad?, México, Cecodes-Océano. 
